\title{
Research on Comprehensive Reinforcement Treatment Technology of Tunnel Entrance Slope in Thick Landslide Stratum
}

\author{
Hui Chen, Shangyu Han*, Penheng Zhang, Dengyuan Kang \\ School of Civil Engineering and Architecture, Nanchang Hangkong University, Nanchang, China \\ Email: `956390718@qq.com
}

How to cite this paper: Chen, H., Han, S.Y., Zhang, P.H. and Kang, D.Y. (2022) Research on Comprehensive Reinforcement Treatment Technology of Tunnel Entrance Slope in Thick Landslide Stratum. Open Journal of Applied Sciences, 12, 224-234. https://doi.org/10.4236/ojapps.2022.122016

Received: January 28, 2022

Accepted: February 18, 2022

Published: February 21, 2022

Copyright $\odot 2022$ by author(s) and Scientific Research Publishing Inc. This work is licensed under the Creative Commons Attribution International License (CC BY 4.0).

http://creativecommons.org/licenses/by/4.0/

\begin{abstract}
The existence of loose landslides not only poses a huge safety hazard to the construction of tunnel entrances, but also significantly increases the difficulty of site construction. In this paper, we investigate the comprehensive slope reinforcement management technology for tunnel entrances in thick landslide strata, using the finite element analysis software ABAQUS to study the slope safety coefficients, displacements and plastic zone changes under different management conditions, propose a design structure for slope stability enhancement in thick landslide strata, and analyse the effect of the application of slope stability enhancement measures for thick landslide strata. The results show that the enhanced design structure is used to enhance slope stability. The results show that after the landslide treatment with the enhanced design structure, the slope safety factor was increased from 0.961 to 1.512 , the maximum horizontal tangential displacement was reduced from $330.2 \mathrm{~mm}$ to $32.74 \mathrm{~mm}$, and the area of plastic zone was significantly reduced, and the landslide support effect was remarkable.
\end{abstract}

\section{Keywords}

Thick Landslide Stratum, Slope Management, Landslide Mechanism, Improvement Measures

\section{Introduction}

When thick landslides exist in engineering, there are often obvious joints between different geotechnical properties, which seriously affect the integrity of the geotechnical body and can significantly increase the probability of engineering hazards such as landslides and gullies [1] [2] [3]. In order to reveal the impact of 
changes in soil parameters on slope stability and to reduce the difficulty of selecting treatment measures, the article investigates the difficulties of tunnel entry and the design of cavern entrance stability enhancement, tunnel entry design and deformation control technology and field monitoring technology for thick landslide strata based on the actual situation of the supporting project. The project research results can not only meet the needs of thick landslide slope stability enhancement, but also reduce the influence factors control, and can also improve the site construction efficiency and save the project cost.

\section{Selection of Physical and Mechanical Parameters}

Combined with the indoor test results, engineering experience values and relevant reference materials and other comprehensive analysis to determine the relevant parameter settings for simulation analysis is shown in Table 1.

\section{Optimization of Reinforcement Treatment Scheme Parameters and Evaluation of Effect}

\subsection{Stability Analysis of the Original Slope}

The stability safety factor $\mathrm{F}_{\mathrm{S}}=0.9034$ of this landslide under the action of self-weight was calculated by ABAQUS finite element software or by establishing a simulation test model under the action of self-weight only (The full name of $F_{S}$ is safety factor of slope stability, $F_{S}$ indicates the slope stability safety factor is the ratio of the slip resistance to the slip force along the assumed slip fracture surface. When the ratio is greater than 1, the slope is stable; when it is equal to 1 , the slope is in ultimate equilibrium; when it is less than 1, the slope is damaged). The horizontal displacement and displacement clouds of the landslide are shown in Figure 1.

The landslide plastic damage zone is mainly distributed in the lower soil body at the foot and top of the slope, especially the stress is more concentrated near

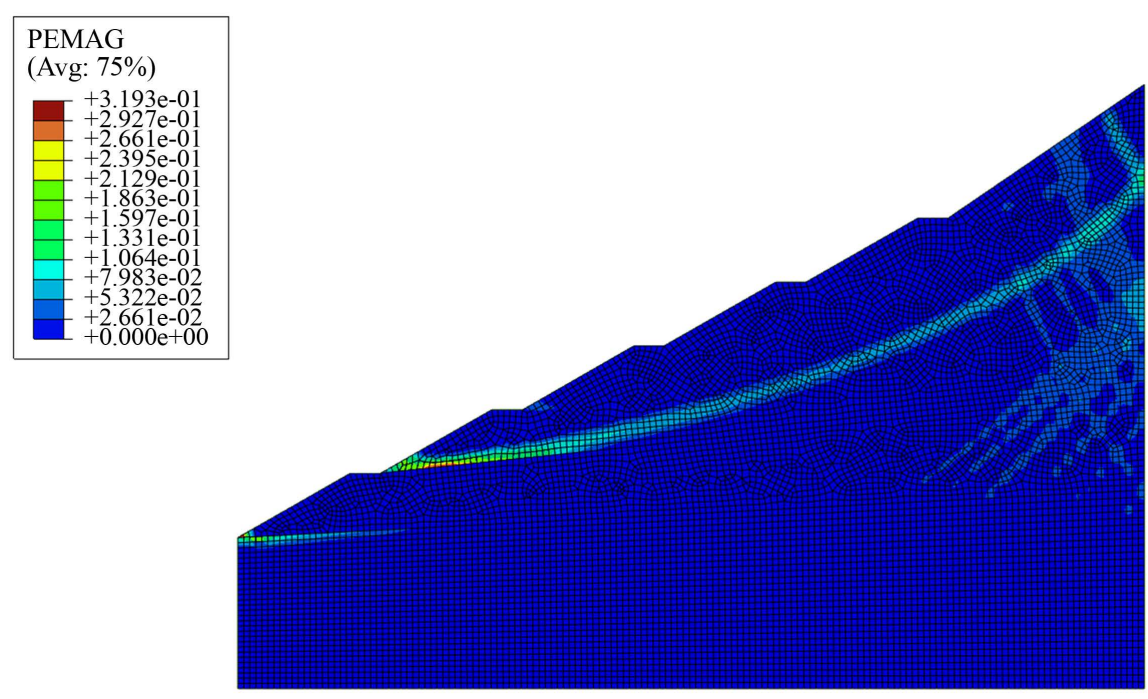

Figure 1. Landslide horizontal displacement and displacement cloud. 
Table 1. Physical and mechanical parameters of rock mass.

\begin{tabular}{|c|c|c|c|c|c|c|}
\hline Materials & $\begin{array}{c}\text { Modulus of } \\
\text { elasticity }\end{array}$ & Poisson's & $\begin{array}{l}\text { Natural } \\
\text { capacity }\end{array}$ & Cohesion & $\begin{array}{c}\text { Angle of } \\
\text { internal friction }\end{array}$ & $\begin{array}{l}\text { present } \\
\text { structure }\end{array}$ \\
\hline Name & $(\mathrm{MPa})$ & & $\left(\mathrm{kN} / \mathrm{m}^{3}\right)$ & $(\mathrm{MPa})$ & $\left({ }^{\circ}\right)$ & Models \\
\hline Gravelly soil layer & 20 & 0.45 & 19.5 & 0.1 & 32.15 & Moore Cullen \\
\hline Marl layer & 2000 & 0.25 & 19.3 & 2.05 & 38.56 & Moore Cullen \\
\hline Shale layer & 3000 & 0.30 & 19.2 & 2.25 & 39.47 & Moore Cullen \\
\hline
\end{tabular}

the intersection of the foot of the slope and the water table line, reflecting a strong sliding trend at the foot of the slope. The maximum shear strain is shown at the shear outlet at the foot of the slope, and the strain concentration and influence range are near the fragmentation zone, and a sliding zone is formed from the top of the slope through to the foot of the slope. From the process of numerical simulation, it can be seen that the stress concentration appears at the top of the slope at first, and then gradually expands downward, and the stress is gradually concentrated at the foot of the slope, and shear damage occurs. The total displacement of the shear outlet at the foot of the slope is the largest, followed by the shear outlet at the top of the slope, and the displacement size decreases towards the middle of the slope respectively. The deformation of the slope body is that the lower part slides first so that the upper part loses support and deforms and slides, resulting in the overall sliding along the sliding zone, which is the traction type landslide. After the foot of the slope is disturbed by the construction, the slope height increases and the anti-slip force decreases, resulting in the deformation of the slope after the slope is cut and cracks appear on the slope surface, followed by the landslide.

\subsection{Reinforcement Programming}

On the premise of ensuring the stability of landslide management, the upper load shedding quickly reduces the gravity of the soil itself, which can prevent the further development of landslide; anti-slip piles have the advantages of good management effect, flexible pile setting and jumping construction method for active landslide without aggravating its activity; steel pipe piles can be used for anti-slip consolidation of landslide, but most of them do not pass through the landslide surface. In this paper, the finite element strength reduction method is introduced to calculate the stability of the landslide, and the calculation results of different support schemes are analyzed and compared to increase the accuracy and reliability of the results [4] [5].

\subsection{Preferred Parameters of Reinforcement Scheme}

\subsubsection{Slope Cutting}

Numerical simulations using ABAQUS software were carried out to obtain the safety coefficient and plastic zone distribution clouds under different slope cutting rates, and the foot of slope displacement and top of slope settlement were 
extracted as characteristic values for comparison and analysis. The variation curves of the slope safety factor under different slope cutting rates are shown in Figure 2, and the distribution of plastic stress in Figure 3.

The safety coefficient increases and then decreases with the increase of the slope rate of the side slope. When the slope rate changes from 1:1.5 to 1:1.65, the slope safety factor increases from 0.865 to 1.157 , and the increase of safety factor reaches $25.2 \%$. When the slope rate reaches $1: 1.75$, the maximum slope safety factor reaches 1.169 , while the increase of slope stability safety factor value starts to slow down. When the slope cutting rate changes from 1:1.85 to 1:1.2, the slope safety factor decreases sharply.

With the change of slope cutting slope rate, the slope is damaged by arc slip, and the maximum displacement is located near the foot of the slope. After the slope is treated with slope cutting, the original stress field is redistributed, and the stress extreme value after redistribution is somewhat smaller, the stress concentration area is obviously reduced, and the concentrated stress is dispersed to

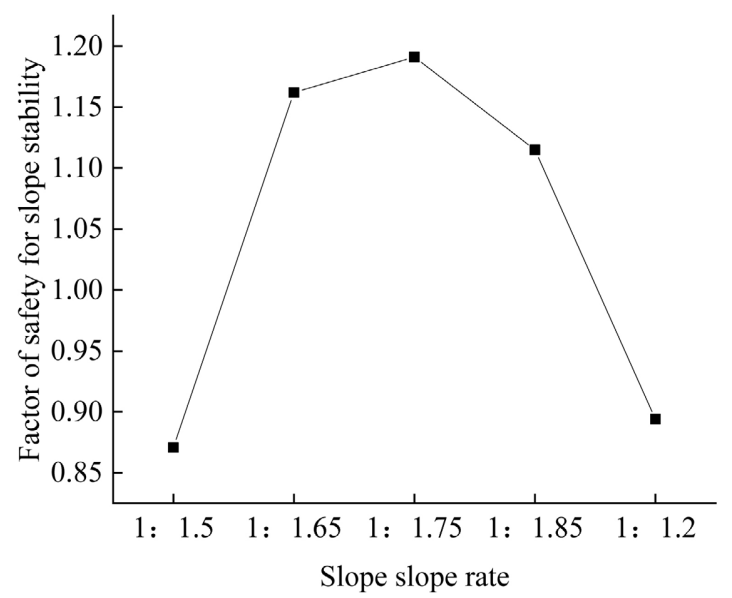

Figure 2. Change curve of slope safety coefficient under different slope cutting rates.

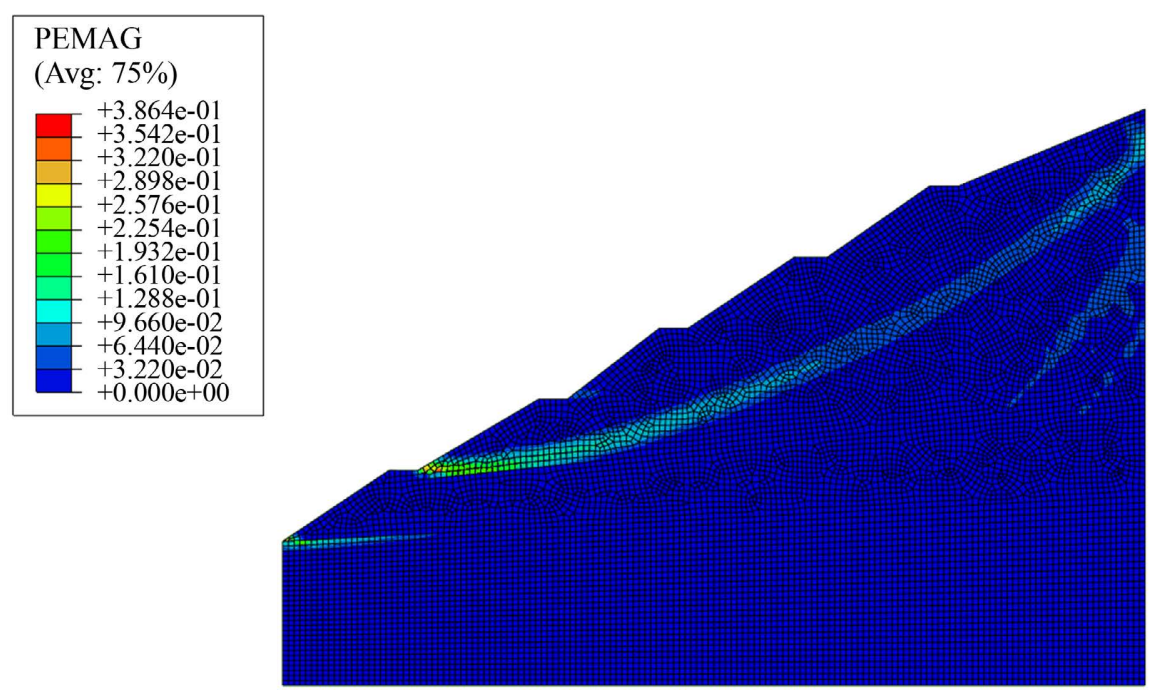

Figure 3. Plastic stress distribution for side slope ratio of 1:1.75. 
the surrounding rocks, which proves that the slope cutting protection plays a certain role in improving the stress distribution of the landslide slope and maintaining the stability of the slope. Combining with the project budget, slope cutting volume and slope stability, the treatment plan with a slope ratio of 1:1.75 is adopted.

\subsubsection{Optimization of Anti-Slip Pile Size}

The landslide stability study of anti-slip piles at different pile positions was carried out. The change curve of the slope safety factor at different pile positions is shown in Figure 4, and the plastic stress distribution is shown in Figure 5.

The safety coefficient of the landslide was significantly improved after the anti-slip piles were placed compared with that without the anti-slip pile treatment, and the slope safety coefficient increased from 1.149 after the original slope cutting treatment to 1.226 . When the position of anti-slip pile changes from the foot to the top of the slope, the slope safety factor increases first and then decreases, and when the pile position is at pile position 4, the slope is most stable and the slope safety factor is 1.226 .

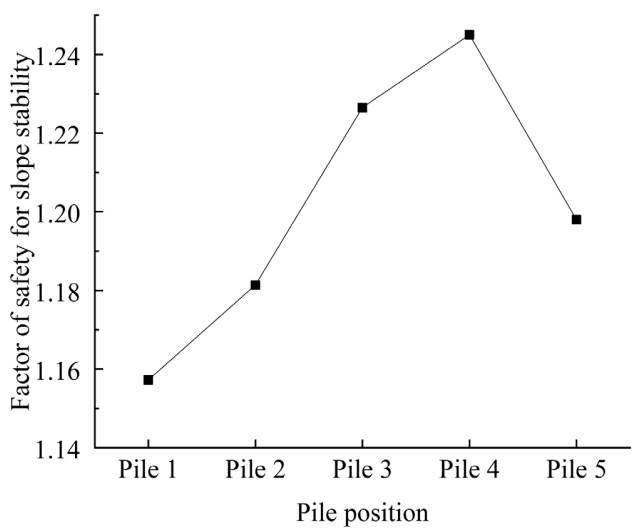

Figure 4. Change curve of safety coefficient of landslide body at different pile positions.

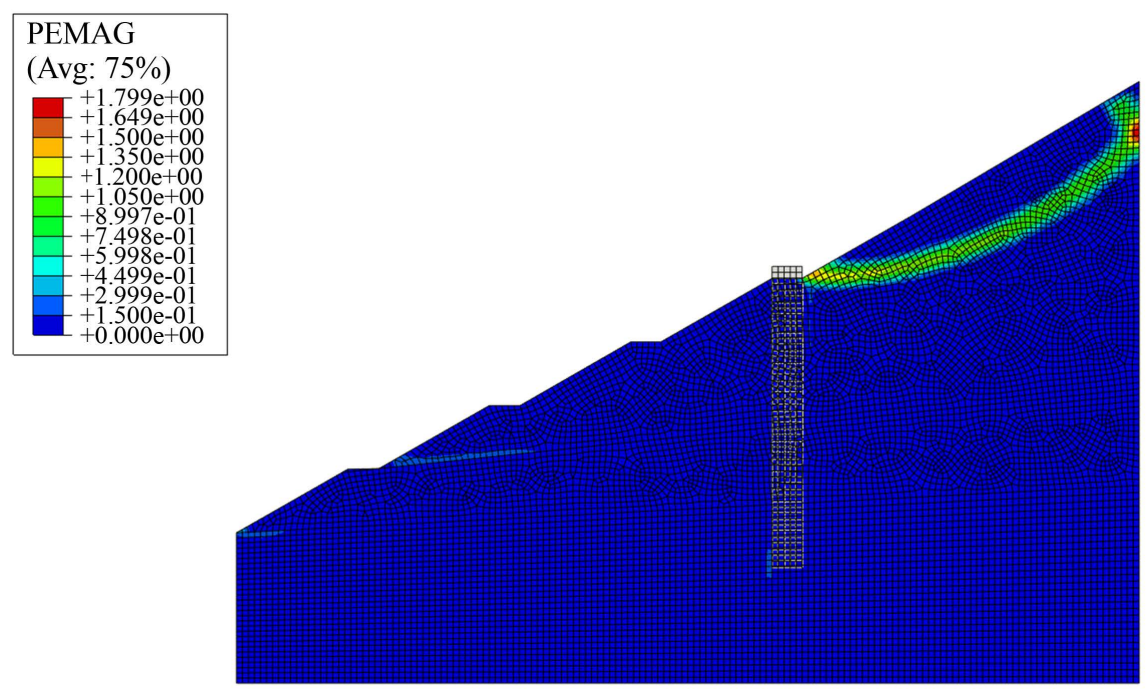

Figure 5. Plastic stress distribution of landslide at pile position 4. 
The location of the piles had an effect on the location and shape of the sliding surface. As the position of piles changes from the foot of the slope to the top of the slope, the position and shape of the sliding surface also changes. Arranging the anti-slip piles in the middle of the landslide can give better play to the anti-slip piles' slide-stopping effect, which is beneficial to the slope stability. When the anti-slip piles are arranged at pile position 5, it can also improve the stability of the landslide to a certain extent, but the anti-slip effect has not reached the best. When gravity load is applied to the slope in the natural state, the vertical displacement of the slope top increases significantly with the increase of the top load, but the increase of settlement decreases gradually, showing the phenomenon of decreasing in order. Considering the slope safety factor and horizontal deformation, it is considered that it is most reasonable to place the anti-slip piles at pile position 4 .

The landslide stability study of anti-slip piles at different cross-sectional areas was carried out. The change curve of the slope safety factor at different cross-sectional areas is shown in Figure 6, and the plastic stress distribution is shown in Figure 7.

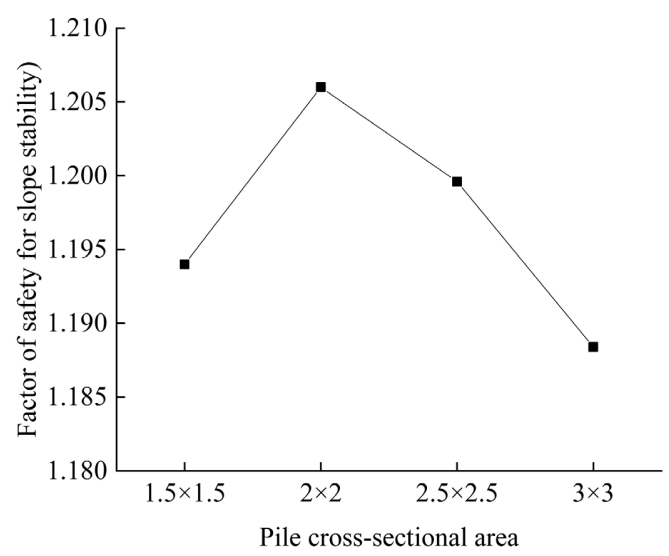

Figure 6. Curve of change of safety coefficient of side slope with different cross-sectional area.

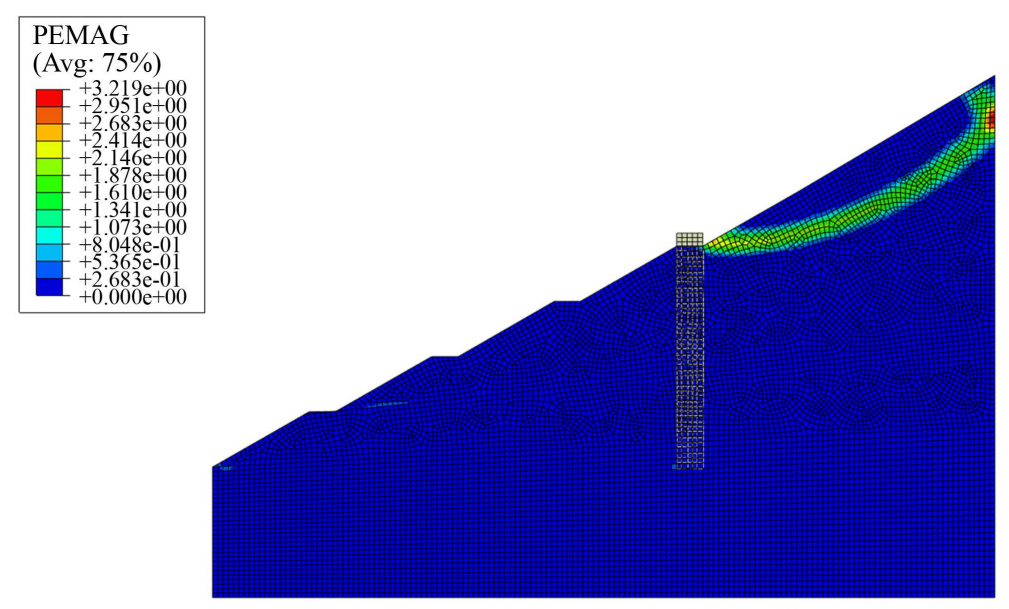

Figure 7. Plastic stress distribution when the cross-sectional area is $2 \mathrm{~m} \times 2 \mathrm{~m}$. 
As the cross-sectional area of the anti-slip pile increases, the position and shape of the sliding surface also change. The position of the sliding surface gradually becomes shallow, and the shape of the sliding surface changes from non-penetration to plastic zone penetration, and then to a sliding surface that crosses the top of the pile, leading to piling front damage. When the pile cross-sectional area is $3 \mathrm{~m}$ $\times 3 \mathrm{~m}$, the plastic zone of the soil slope is not penetrated, but the soil slope at the top of the pile is cracked and the cracking is larger. At the same time, the upper soil slides due to extrusion; when the pile is located at pile position 2, the anti-slip pile bends at the position of the sliding surface due to shear, and the plastic zone is the largest in the middle of the slope, which is in line with the law that the plastic zone gradually increases from the slope to the slope. Considering the slope safety coefficient and horizontal deformation, it is considered that it is most reasonable to design the anti-slip pile cross-sectional area as $2 \mathrm{~m} \times 2 \mathrm{~m}$.

\subsubsection{Optimization of Steel Pipe Pile Length Size}

When the length of the embedded end of the steel pipe pile increases from $10 \mathrm{~m}$ to $20 \mathrm{~m}$, the safety factor of the slope gradually increases and the landslide becomes more stable. The stress is highly concentrated in the embedded part of the steel pipe pile in contact with the mudstone layer, which means that the steel pipe pile transfers the upper thrust to the lower stable layer of mudstone. And the greater the length of steel pipe pile, the greater the depth of stress transfer, when the pile length reaches $20 \mathrm{~m}$, the depth change is less obvious. And in the steel pipe pile length of $10 \mathrm{~m}$, its anchorage depth is shallow, the stress transfer is not obvious, indicating that the steel pipe pile length is too shallow so that the pile and soil together with the slip. Therefore, the pile length of $20 \mathrm{~m}$ is selected by considering the economic factors.

\subsection{Comprehensive Analysis}

When the landslide slides at the early stage, the contribution of steel pipe piles to the overall stability of the soil is greater than that of anti-slip piles, and with the further sliding of the landslide, the role of anti-slip piles begins to dominate. The amount of landslide displacement has a greater relationship with the slope cutting rate, anti-slip pile diameter and steel pipe pile, which shows that the larger the slope cutting rate and the smaller the anti-slip pile diameter, the larger the landslide displacement. After the anti-slip piles manage the landslide, the landslide and the soil body are an interactive whole, and the anti-slip piles will also be displaced with the soil sliding.

To sum up, the slope is cut according to the slope rate of 1:1.75, and anti-slip piles are laid along the tunnel with a diameter of $2 \mathrm{~m}$. The anti-slip piles are constructed by dry drilling with rotary drilling, and the holes are drilled at intervals of 2 holes. The steel pipe pile is made of hot-rolled seamless steel pipe with wall thickness of $6 \mathrm{~mm}$ and diameter of $\phi 108$, and the length of steel pipe pile is $20 \mathrm{~m}$. After calculation, it can be concluded that the stability safety coefficient of landslide under each working condition has been improved to a large 
extent compared with that before treatment, and the safety coefficient can reach 1.512 when comprehensive treatment plan is adopted, which meets the requirements of landslide treatment.

\section{Engineering Reinforcement Effect}

The monitoring design needs to take into account the monitoring purpose and monitoring content in different periods and make a comprehensive analysis of the rationality, and the whole monitoring process must be kept continuous and complete. In the construction period and the early use of monitoring content mainly includes the slope and its support structure monitoring [6]. The project has now obtained part of the monitoring data, the subsequent tunnel construction process and road operation will continue to observe, monitoring cycle should be no less than two years (after the project is completed and put into use to start counting), and timely analysis of feedback data to ensure the safety of the project. Take a section as an example, the surface settlement and the maximum daily average settlement rate over time as shown in Figure 8 and Figure 9.

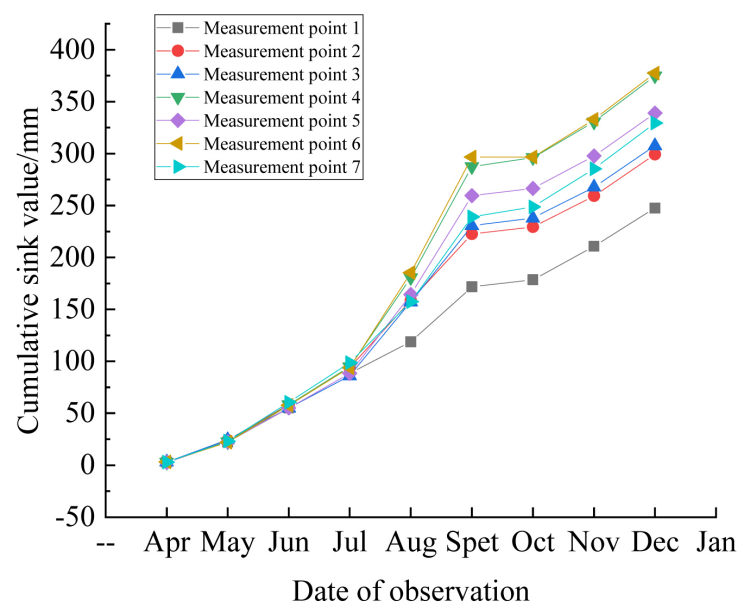

Figure 8. Surface subsidence versus time graph.

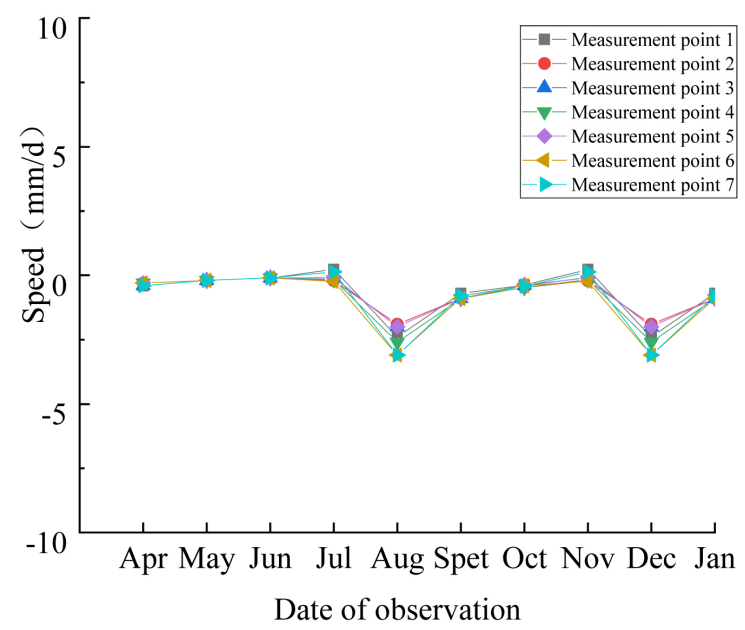

Figure 9. Surface subsidence rate versus time graph. 
The accumulated maximum value of the surface subsidence observation section at the right exit of the Mangerzai tunnel is $374.9 \mathrm{~mm}$, and the maximum rate is $-3.1 \mathrm{~mm} / \mathrm{d}$. The shape of the surface subsidence versus time curve is very similar at all measurement points. The ground surface was disturbed by the slope stabilization and continued to settle in the early stage, and then stabilized

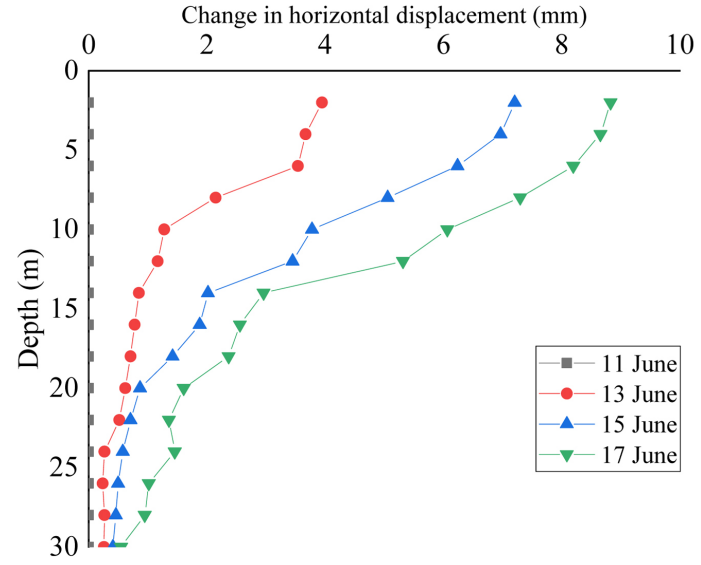

Position 1
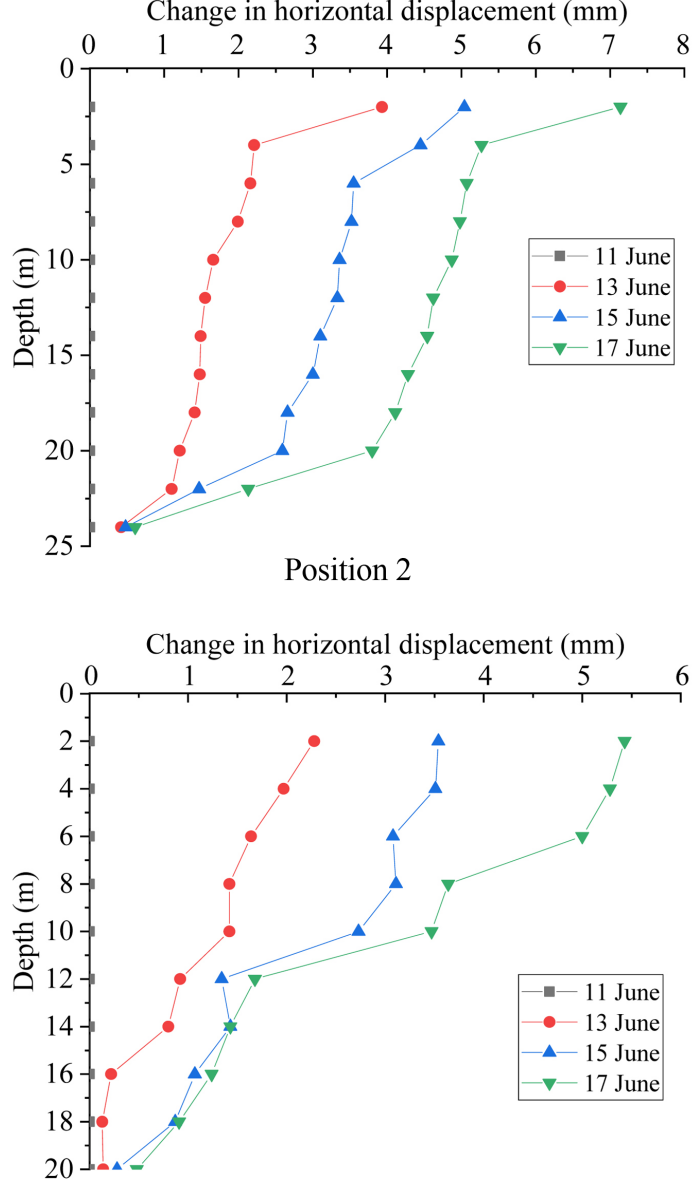

Position 3

Figure 10. Cumulative change of deep horizontal displacement-depth relationship graph. 
in September when most of the slope stabilization works were completed, and the tunnel excavation started in October, resulting in obvious fluctuations in the settlement rate. As can be seen from Figure 9, the soil at the exit of the right cavern of the Mangerzai Tunnel is loose and easily affected by construction and blasting. With the construction of slope management and tunnel excavation, the subsidence fluctuation of each measurement point on the ground surface fluctuates from August to December, and the subsidence rate fluctuates occasionally but tends to be stable in general. Up to now, the monitored data show that the sinking of the vault and the sinking rate of each monitoring section at the exit of the Mangerzai Tunnel is within the allowable relative displacement values of the corresponding surrounding rock level, and no abnormal situation has occurred. No major surface settlement occurred during the whole construction stage, indicating that the slope support scheme is reasonable and within the design requirements of deformation.

In order to further analyze the stability of the support structure and slope deformation, the deep horizontal displacement measurement points 1 - 3 are selected for research and analysis. A plot of the cumulative change in deep horizontal displacement-depth relationship for the different measurement points is shown in Figure 10.

As shown in Figure 10 the maximum horizontal displacement of measurement point 1 is $8.97 \mathrm{~mm}$, measurement point 2 is $8.38 \mathrm{~mm}$, and measurement point 3 is $10.62 \mathrm{~mm}$. With the gradual increase of depth, the deformation gradually decreases, and the deformation becomes stable at the depth of about $30 \mathrm{~m}$, $25 \mathrm{~m}$ and $20 \mathrm{~m}$ respectively. At the early stage of monitoring, the deformation of each measurement point is relatively small, but with the construction, the displacement of each measurement point grows obviously, from the location of measurement points, the displacement of No. 1 measurement point, which is closest to the perimeter wall of the tunnel, is the largest, and the displacement of No.3 measurement point, which is farthest away, is the smallest. The shape of the deep horizontal displacement curve of each measurement point is very similar, and the maximum displacement occurs near the surface. With the increase of monitoring depth, the deep horizontal displacement basically goes through the process of "sharp change-slow change". During the monitoring period, no abnormal phenomena such as cracks appeared on the slope, and the displacement at each point tended to be stable.

\section{Conclusions}

1) Using the finite element analysis software ABAQUS to establish simulation analysis to simulate the landslide formation process, the overall landslide displacement, maximum shear strain, relative displacement distribution pattern and change trend were carried out. Further, based on the summary of the site investigation report and indoor physical and mechanical tests on the formation factors of the landslide, it was concluded that the landslide occurred under the 
joint action of the fracture zone, human engineering activities and rainwater.

2) ABAQUS finite element software is used to establish the corresponding simulation test model based on the indoor model test to analyze the stability of the landslide body before and after reinforcement under different support schemes, and propose a slope management scheme that can meet the management requirements.

3) The results of slope monitoring show that the horizontal displacement of the monitoring points near the excavation surface is larger than the horizontal displacement of the monitoring points near the excavation surface, and the horizontal displacement of the top of the slope is basically the same as the displacement of the deep part of the slope body. Overall, the slope displacement is controlled within a small range. The numerical simulation to optimize the design is feasible. The conclusion of the study can provide a reference for the design and research of landslide management projects of high slopes with similar conditions in the area.

\section{Acknowledgements}

Thanks for the support of the National Natural Science Foundation of China (Grant No. 52068054) and the project supported by the graduate innovation fund of Nanchang University of Aeronautics (Grant No. YC2020-093).

\section{Conflicts of Interest}

The authors declare no conflicts of interest regarding the publication of this paper.

\section{References}

[1] Hou, S.J., et al. (2021) Model Test on Tunnel Slope Stability of Talus-Type Rock Mass under Excavation and Rainfall. Frontiers in Earth Science, 11, 590-600. https://doi.org/10.12677/AG.2021.115054

[2] Fu, S., Chen, L.X., Woldai, T., Yin, K.L., Gui, L., Li, D.Y., Du, J., Zhou, C., Xu, Y. and Lian. Z.P. (2020) Landslide Hazard Probability and Risk Assessment at the Community Level: A Case of Western Hubei, China. Natural Hazards and Earth System Sciences, 20, 581-601. https://doi.org/10.5194/nhess-20-581-2020

[3] Yang, Y.-C., Xing, H.-G., Yang, X.-G., et al. (2018) Experimental Study on the Dynamic Response and Stability of Bedding Rock Slopes with Weak Interlayers under Heavy Rainfall. Environmental Earth Sciences, 77, Article No. 433. https://doi.org/10.1007/s12665-018-7624-y

[4] Wei, C., Wang, J. and Cheng, F. (2019) Comparative Study on Calculation Methods for Stability Evaluation Based on BIM Models of Soil Landslides. IOP Conference Series. Earth and Environmental Science, 304, Article No. 042076. https://doi.org/10.1088/1755-1315/304/4/042076

[5] Dini, B., Manconi, A. and Loew, S. (2019) Investigation of Slope Instabilities in NW Bhutan as Derived from Systematic DInSAR Analyses. Engineering Geology, 259, Article No. 105111. https://doi.org/10.1016/j.enggeo.2019.04.008

[6] Zhang, Q., et al. (2019) Study on Slope Stability Due to the Influence of Excavation of the High-Speed Rail Tunnel. Geomatics, Natural Hazards \& Risk, 10, 1193-1208. 